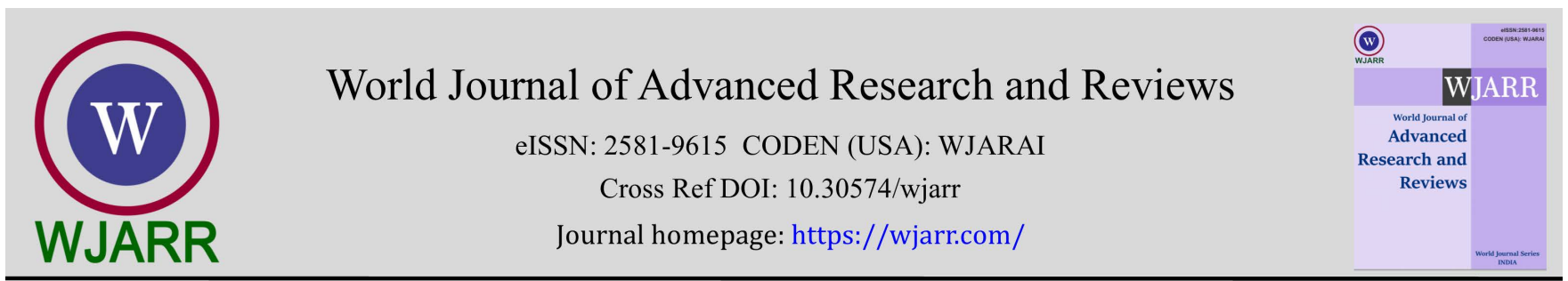

(RESEARCH ARTiClE)

Check for updates

\title{
Using inverted 4-D seismic and well data to characterise reservoirs from central swamp oil field, Niger Delta
}

\author{
Emmanuel Onyeka Ezim 1, 2,*, Abel Idowu Olayinka ${ }^{2}$, Michael Oladunjoye ${ }^{1}$, Izuchukwu Ignatius Obiadi ${ }^{3}$ and \\ George-Best Azuoko 4 \\ ${ }^{1}$ Department of Geology, Gregory University, Uturu Abia State, Nigeria. \\ 2 Department of Geology, University of Ibadan, Ibadan, Nigeria. \\ ${ }^{3}$ Geological Science Department, Nnamdi Azikiwe University, Awka, Nigeria. \\ ${ }^{4}$ Department of Earth Science, Alex Ekwueme Federal University, Ndufu-Alike Ikwo, Abakaliki, Ebonyi State, Nigeria.
}

World Journal of Advanced Research and Reviews, 2022, 13(02), 185-200

Publication history: Received on 20 December 2021; revised on 03 February 2022; accepted on 05 February 2022

Article DOI: https://doi.org/10.30574/wjarr.2022.13.2.0083

\begin{abstract}
Monitoring of reservoir properties prior to well placements and production is a requirement for optimisation and efficient oil and gas production. This is usually done using well log analyses and 3-D seismic, which are often prone to errors. However, 4-D (Time-lapse) seismic, incorporating numerous 3-D seismic surveys of the same field with the same acquisition parameters, which portrays the transient changes in the reservoir due to production effects overtime, could be utilised because it generates better resolution. There is however dearth of information on the applicability of this approach in the Niger Delta. This study was therefore designed to apply 4-D seismic, well-log and geologic data in monitoring of reservoirs in EK field of the Niger Delta. It aimed at locating bypassed accumulations, and ensuring effective reservoir management. The Field (EK) covers area of about $1200 \mathrm{~km}^{2}$ belonging to the early (18ma) Miocene. Data covering two 4-D vintages acquired over fifteen-year interval were obtained from oil companies operating in the field. The data were analysed to determine the seismic structures, horizons, Well-to-Seismic Tie (WST), and wavelets. Well logs and production history data from fifteen selected wells were also collected from the Oil companies. Formation evaluation, petrophysical analysis and inversion alongside geological data were undertaken using Petrel, Shell-nDi, Techlog and Jason Software. Well-to-seismic tie, formation evaluation and saturation monitoring using petrophysical and geological data and software were used to find bypassed hydrocarbon prospects. The seismic vintages were interpreted, and the amounts of change in the reservoir were defined by the differences in Acoustic Impedance (AI) inversions of the base and the monitor seismic. AI rock properties were estimated from all the seismic amplitudes using controlled sparse-spike inversion. The estimated rock properties were used to produce AI maps. The structural analysis showed dominance of NW-SE trending rollover collapsed-crest anticlines in EK with hydrocarbons trapped northwards. There were good ties in wells EK 27, 39. Analysed wavelets revealed consistent amplitude and phase for the WST hence, a good match between the inverted impedance and the well data. Evidence of large pay thickness, ranging from $2875 \mathrm{~ms}$ (11420 TVDSS-ft) to about $2965 \mathrm{~ms}$, were found around EK 39 well with, good yield properties. The comparison between the base of the AI and the current monitor and the generated AI maps revealed zones of untapped hydrocarbons as well as assisted in determining fluids movement. The inverted sections through EK 27, 39 (within $3101 \mathrm{~m} \mathrm{-} 3695 \mathrm{~m}$ ), indicated depletion in the reservoirs. The extent of the present non-uniform gas-oil contact and oil-water contact movements were from 3554 to $3575 \mathrm{~m}$. The 4-D seismic approach led to better reservoir characterisation, well development and the location of deeper and bypassed hydrocarbon reservoirs.
\end{abstract}

Keywords: Reservoir monitoring; 4-D Seismic; Well placements; Petrophysical Analysis; Niger Delta Basin

\footnotetext{
${ }^{*}$ Corresponding author: Emmanuel Onyeka Ezim

Department of Geology, Gregory University, Uturu Abia State, Nigeria.

Copyright $(2022$ Author(s) retain the copyright of this article. This article is published under the terms of the Creative Commons Attribution Liscense 4.0.
} 


\section{Introduction}

Monitoring of reservoir properties prior to well placements and production is a requirement for optimisation and efficient oil and gas production. This is usually done using well log analyses and 3-D seismic, which are often prone to errors. However, 4-D seismic, incorporating numerous 3-D seismic surveys overtime, could be utilised because it generates better resolution. There is however dearth of information on the applicability of this approach in the Niger Delta. This study was therefore designed to apply 4-D seismic inversion, and petrophysical data in monitoring of reservoirs in EK fields of Niger Delta.

The Niger Delta Basin is a major petroleum province for oil and gas exploration in Nigeria. Petroleum exploration activity in Niger Delta has resulted in the acquisition of well log records and several 3-D seismic data. It has been observed that the remaining undiscovered oil reserves are just about as large as those already consumed (Energy Information Administration, 1998a; Waal and Calvert, 2003) [9, 32]. That is a vast amount of oil, that are remaining and are hard to explore, that is why it is imperative to work on how to recover them reliably and efficiently. The need for accurate description of the petroleum reservoir and locating untapped oil and gas accumulations is critical to reservoir management. Yet, due to the complex nature of reservoir heterogeneity with time, obtaining accurate description of the reservoir and improving recovery is a big challenge. Next is the need to monitor the evolution of existing reserves over time due to production as pressure, saturation, etc, changes; to ensure optimum production. Also, there is the utmost need for accurate prediction of fluid flow in regions away from well control. This study is focused on bridging the gap in interpreting recent 4-D seismic in the Acoustic Impedance (AI) domain instead of the usual amplitude domain. As compared to its application in developed countries of the world like US, UK and Norway, 4-D seismic has not been extensively used in the Niger Delta to identify areas of bypassed and un-drained hydrocarbons, monitor the movements of reservoir fluids as production goes on, improve the existing geologic model, and more cost-effective field operations.

\section{Aim and Objectives}

With the use of various data and geophysical techniques, the aim of this study is to monitor the production changes of Niger Delta (Central Swamp - EK) oilfield reservoirs, and determine the extent of fluid contact movements using 4-D seismic, and well data, in order to optimize wells placement, improve recovery and find new prospect. It was achieved with these specific objectives:

- $\quad$ To build the structural model of the study area, integrating and evaluating well information with seismic data to obtain Well- to- Seismic Ties (WST) including existing velocity data and synthetic-seismic match in EK Fields.

- To obtain and estimate acoustic impedance rock property from seismic amplitudes using model-based inversion algorithm. To also produce several Acoustic Impedance (AI) maps of the inverted base, monitor and difference cube showing the effects of production in the study area.

- To Track transient changes in E2000 reservoirs due to production effects and determine expected hydrocarbon response, potential fluid contact characteristics and areas of by-passed production, or inefficiencies in the production process. Use the results to predict new prospect, propose perforation depths, and optimize seismic interpretation strategy plus correlation.

- To carry out a general assessment of reservoir characterization and applying the results to the Niger Delta clastic reservoirs for better history-matching, enhanced prospect definition and locating bypassed hydrocarbon pay.

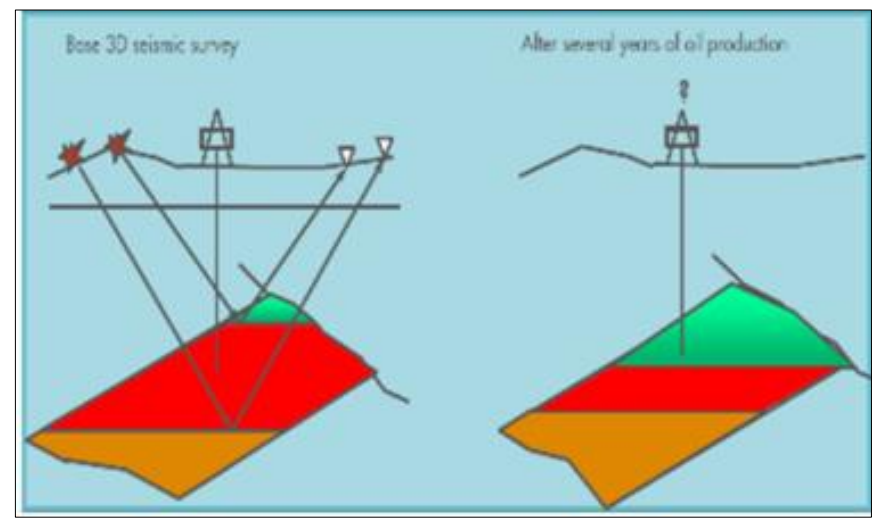

Figure 1 A cartoon showing a Base 3-D seismic survey and a time lapse survey. After several years of oil production (Staples et al., 2006) [28] 
Generally, the objective in optimum field development is to lengthen the life span of the field, prevent water invasion, and recover as much hydrocarbon as possible. By recording 3-D seismic data over the field at various time intervals, which may be from months to years, the fourth dimension (calendar time) were introduced to the analysis of the data, thus the term 4-D seismic method to describe the time-lapse 3-D seismic exploration. Figure 1 shows a cartoon of a 4-D seismic survey.

\subsection{Literature Review}

In marine 4-D seismic acquisition, Eiken et al. (2003) [8] demonstrated that dense streamer towing complemented by accurate data regularization can reduce the Normalized Root Mean Square (NRMS) repeatability error to about 6\%, which corresponds to the minimum theoretical 4-D threshold in ideal condition as described by Calvert (2005) [4].

For land acquisition, Widmaier et al. (2003) [34] described a 4-D acquisition strategy that has become that of international standard. The strategy was based on high density 3-D (HD-3D) principles yielding data, which is very robust and is easily modified for specific reservoir challenges and survey locations. If the location of given shot is repeated between successive surveys, then the repetition of all source-receiver azimuths will guarantee that receiver positions are also repeated. The criterion is specified because source-receiver azimuth differences are particularly easy to "Quality Check (QC)" during acquisition and processing. In measurements, the same source and receiver location (initial location same as the one after some time duration), are used. Same number of fold and similar processing methods usually called "apple-for-apple process".

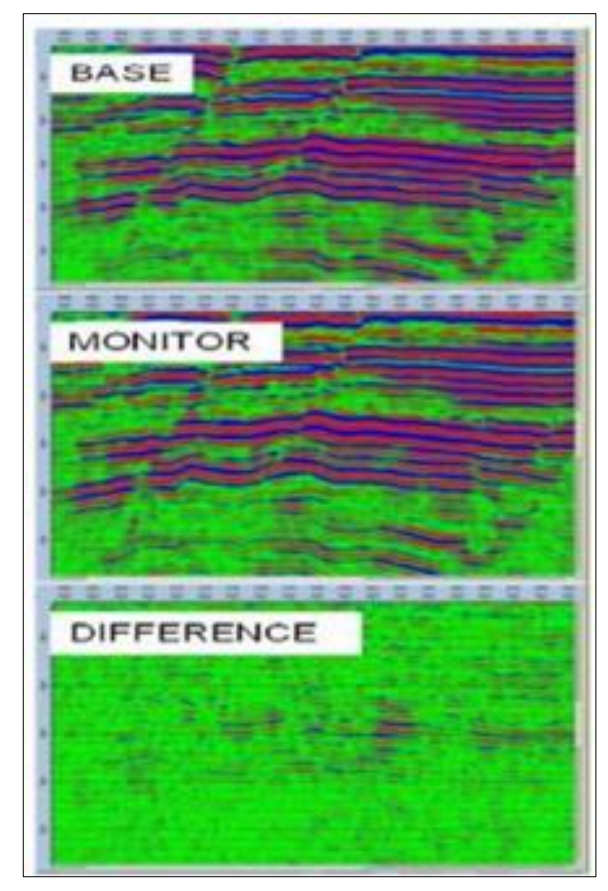

Figure 2 Seismic section through the base (recently processed 1991 3-D seismic vintage), monitor (2012 reshoot) and difference seismic volume (Aikulola et al., 2011) [1]

Processing and imaging time-lapse datasets requires great care and attention to detail, in order to attenuate the 4-D noise caused by changes in acquisition parameters or environmental conditions, and to emphasize the 4-D signature of the reservoir caused by changes in fluid, pressure and stress. Some processes with particular application to 4-D projects include: Static, Regularization, 4-D binning, De-striping, Matching, etc.

An example of 4-D processing, where comparison of the base and monitor seismic were made was reported by Aikulola et al. (2011) [1]. Figure 2 is a seismic section through the base, monitor and difference showing the result of the difference analysis. The processing resulted in optimized 4-D seismic dataset with an average RMS Repeatability Ratio (RRR) of 0.28 . It was expected that the new 4-D seismic data would improve well reservoir management and optimize field development plan for the prior field. An interpretable seismic data with RMS Repeatability Ratio (RRR) of 0.28 were obtained after 4-D seismic processing. The main processing steps in achieving the required repeatability between the base and monitor surveys are combined residual statics derivation, depopulation by trace pair selection and 
application of matching filters. The volumes delivered are the base, monitor and difference seismic data (Figure 2) which would be used for well reservoir management and optimization of the field development plan.

In interpretation, measurements are aimed at measuring or estimating from 4-D seismic data, the reservoir properties that are affected as a result of production induced changes (difference) in the reservoir (Tian et al., 2012) [29]. The 4-D data interpretation and measurement usually are performed in seismic space on a seismic interpretation system.

The Difference Volume: On a difference section, the constant geology is differenced away and the reservoir changes become more visible. Small reservoir faults may also become visible in a difference section. The difference amplitude in an oil field usually will be proportional to $\phi . \Delta S_{w} . h$, where $\mathrm{h}$ is the height which may be the full reservoir thickness or only the oil-column change, $\phi$ is the effective porosity and $\Delta S_{w}$ is the change in fluid saturation. The difference section can be important in revealing reservoir architecture details and also provide unique information regarding permeability away from the wells (Figures 2).

According to Tian et al. (2012) [29], Time shift is necessary in order to match the phase and time of a seismic dataset from amplitude map. Because reservoir changes causes velocity changes, time shifts are important indicators. Time shifts measured over a defined reservoir interval may be robust in the presence of wavelet differences and static shift. By correlating the baseline and the monitor surveys, the time shift across the entire reservoir could be determined, by estimating wavelet effects and the correlation or time-shift difference between the measurement below the particular reservoir and the one above it.

It is well established that 4-D repeatability depends strongly on repeating the acquisition parameters, such as source and receiver positions, wavelet and noise conditions, and subsequent processing. From seismic data, prediction of trace repeatability for given acquisition could be done. If two traces are time shifted, the result can yield largely surprisingly large differences.

In another example, 4-D challenges inherent in an onshore environment due to urbanization and ways of tackling them were demonstrated, by Lumley (2004), Omudu et al. (2007b) and Aikulola et al. (2011) [16, 18, 1]. These challenges include: statics, noise, further repeatability issues, etc.

\subsection{Applications and Benefits of the 4-D Seismic}

Managing production and imaging bypassed prospects are some of the technical and economic benefits of 4-D seismic methods. Other known applications were also, elaborated in the research of the following authors (Lumley et al., 1999; Lumley, 2001; Burkhart et al., 2001; Gan et al., 2004, Detomo et al., 2009) [14, 15, 3, 10, 6].

\subsection{Time-lapse Inversion}

Seismic Inversion is thus, the transformation of seismic amplitude cubes into elastic (or acoustic) impedance cube. According to Treitel and Lines (1994) [30], the inversion transformed reflection data into reservoir rock property description that is quantitative. The physical parameters involved in seismic inversion are impedance, velocity and density; others are lambda and shear modulus. Acoustic impedance inversion can be seen as a form of deconvolution (Russell, 1988; Lorenzen, 2000; Qing, 2002; Zou et al., 2002; Omudu et al., 2007a) [23, 13, 20, 35, 17]. An important part in the inversion procedure is the estimation of the seismic wavelets. There are pre-stack and post-stack inversion methods. Here, the focus is on pre-stack inversion and it involves applying the inversion at well locations to verify the inversion parameters and optimize the seismic scaling. The output volumes of pre-stack inversion are acoustic impedance, shear impedance and density.

Inversion of 4-D data can be carried out in a number of different ways. In this work, the individual inversion scheme was employed as compared to that by Lorenzen (2000) [13]. It involves the inversion of individual base and monitor data sets to impedance models using the constrained sparse-spike inversion algorithm, which are then differenced to obtain a time-lapse impedance model. The inversion consists of a regularized linear inversion calculation which determines the simplest possible model that is able to fit the observed data.

The capabilities of seismic inversion for reservoir characterization have been investigated by several authors including: Ross and Suat-Altan (1997), Qing (2002) and Omudu et al., (2007c) [22, 20, 19]. In these papers, integration of acoustic properties, core and wire-line log data combined with an understanding of rock physics permit the key uncertainties of hydrocarbon in place, reservoir connectivity, and consequent production challenges to be addressed. These researchers suggest that appropriate integration will facilitates effective reservoir management and lead to the eventual application of technologies such as 4-D seismic. Sarkar et al. (2003) [24] assessed the merits of different inversion workflows by 
using a synthetic 4-D data set and comparing models resulting from the inverse calculations with actual impedance models.

The study demonstrated the importance of coupling the inversion of base and monitor surveys to mitigate the impact of inherent non-uniqueness in seismic data inversion.

In accessing the feasibility of 4-D seismic monitoring projects, Blonk and Brehen (1998) [2], show an early example of how to access the field and recognise cases that are favourable to the use of 4-D seismic monitoring of the reservoir, taking proper consideration of noise levels. This approach, which helps in proper planning for repeated or monitored surveys, can help enhance the chances of success for monitoring fluid contacts and reservoir dynamics. The 4-D seismic anomalies are characterized as differences between time-lapse 3-D data that are present after cross-equalization as exemplified by Figure 3. Calibration of these anomalies often is ambiguous, in that, they may be attributable to changes in one or more of the reservoir conditions, such as change in fluid saturation caused by water displacing oil, pore pressure change caused by injection, or a temperature change caused by steam injection (Tura and Lumley, 1999) [31].

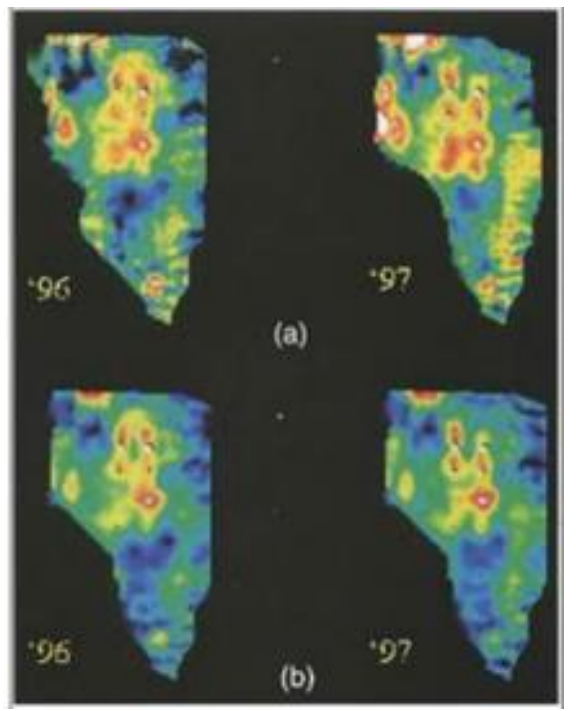

Figure 3 Amplitude extractions along a time slice from two time-lapse 3-D seismic data recorded in 1996 and 1997 ,

(a) before and (b) after cross-equalization (Ecker et al., 1999) [7]

\subsection{Controlled Sparse-Spike Inversion (CSSI)}

The most common deterministic methods are represented by: Sparse spike inversion that is controlled. This is an impedance inversion and the goal is to find a model that is reflection coefficients $r(t)$ given that seismic data $x(t)$ and source wavelet $\mathrm{w}(\mathrm{t})$ as input, and then calculate impedance $\xi(\mathrm{t})$ from the model. Also, the concept and the methodology of CSSI can be found in Chi et al. (1984) and Lorenzen, (2000) [5, 13]. Lorenzen (2000) [13], showed examples of inversion using wavelets estimated with or without well log information.

The inversion replaces the seismic trace by a pseudo acoustic impedance trace at each Common Depth Point (CDP) position. Note that the sparse spike assumption implies, however, that thin bed geometry will not always be reach in the most optimal way.

\subsection{Description of the Study Area}

The EK Field is situated in the Central Swamp depositional belts of Niger Delta Basin which, is situated in the Gulf of Guinea and extends throughout the Niger Delta province as defined by Reijers (2011) [21]. Situated some $17 \mathrm{~km}$ southeast of Yenegoa ( $90 \mathrm{~km}$ west of Port Harcourt), in one of the Niger Delta's Oil Mining Leases (OMLs). It lies within Latitudes $4^{0} 37^{1} \mathrm{~N}$ and $5^{0} 00^{1} \mathrm{~N}$; Longitudes $6^{0} 10^{1} \mathrm{E}$ and $6^{0} 37^{1} \mathrm{E}$, covering an area of about $1200 \mathrm{~km}^{2}$ and belonging to the early Miocene (18 ma). The study area is located in the seasonally flooded freshwater central swamp area (Figures 4). The field was discovered in 1961 by EK -01 well. To date, a total of about 40 wells have been drilled, 34 of which penetrated the E2000 reservoir. Seven of these wells are water injection wells, three are water producers, twenty five are oil producers, two are gas producers and five were either abandoned or sidetracked. The E2000 is oil and gas bearing while the D6200, F1000, F2000 are Natural Gas (NAG) reservoirs (SPDC, 2013). The 3-D baseline survey was acquired between July and October 1997, while the monitor survey was acquired between January and July 2008 , by 
the company, operating in the area with the objective to optimize the subsurface image of the proven oil bearing structures in the prospect area (Aikulola et al., 2011) [1]. Figure 4, shows the map of the study area from a result of the design from the ArcGIS software. The map shows the position and features of the field.

The regional Geology and stratigraphy had been studied by many authors including: Short and Stauble (1967); Reijers (2011) [21]. From Eocene to the present, the Niger Delta has prograded southwestward, forming depobelts that represent the most active portion of the delta at each stage of its development. These depobelts form one of the largest regressive deltas in the world with an area of about $300,000 \mathrm{~km}^{2}$, a sediment volume of $500,000 \mathrm{~km}^{3}$ and a sediment thickness of over $10 \mathrm{~km}$ in the basin depocenter (Kulke, 1995) [12].

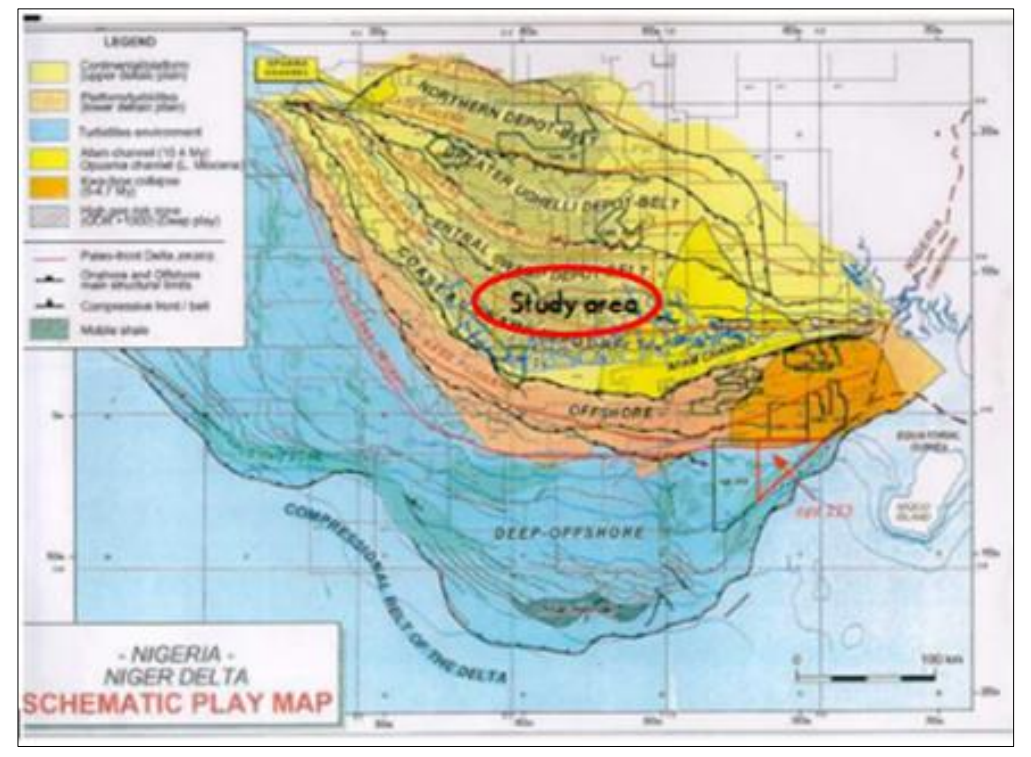

Figure 4 Niger Delta (Nigeria) location showing the Study area $\bigcirc$ within the map (Adapted from SPDC Geomatics, 2008) $[25,13]$

The Niger Delta Province contains only one identified petroleum system which is referred to as the tertiary Niger Delta (Akata - Agbada) Petroleum System (Kulke, 1995; Haak, et al., 2000; Reijers, 2011) [12, 11, 21]. Petroleum exploration is also expanding, especially in deepwater offshore.

\section{Material and methods}

Data covering two 4-D seismic vintages acquired over fifteen-year interval were obtained from oil companies operating in the field. Well logs and production history data from fifteen selected wells were also collected from the Oil companies. Formation evaluation, petrophysical analysis and inversion alongside geological data were undertaken using Petrel, Shell-nDi, and Jason Software. In this stage, attribute derived from the seismic data were integrated with well derived rock properties to map the earth's physical properties measured away from well bore into the field covered by the seismic. One key step is to identify which seismic attributes, individually or in combination, provide the optimal correlation with the rock attributes. Hence, the data were analysed to determine the seismic structures, horizons, Wellto-Seismic Tie (WST), and wavelets. Also, seismic inversion were run on the two vintages of the seismic data (the base and the monitor) using Jason Geosciences work bench (JGW) software, and the acoustic impedance and other attributes were generated for interpretation and for better delineation of the reservoirs, and inferring changes in terms of fluid dynamics and saturation.

\subsection{Structural analysis}

This analysis was carried out. A good understanding of the fault positions and orientations is critical for the effective drilling planning in order to maximize efficiency of drilling and hydrocarbon extraction. Faults were picked using the Petrel software, on vertical sections along the direction of maximum transport and correlated along the fault trace on semblance slices. The faults sticks were correlated with multiple semblance slices at an interval of 0.5 ms two-waytravel time to constrain fault shape and validate vertical correlation of faults in a 3-D visualization tool. The resultant faults sticks were then modelled to produce the corresponding fault surfaces which were used to delineate the 
geological structural trend in the study area. This was carried out with the nature of the geology of the basin, (structural styles) of the area in mind.

Fault interpretation was performed using cross section (every 4th inline) and time slices generated from the variance cube. The continuity of the fault segments and their assignments were rigorously checked on the variance time slices and tied to the well data. The observed fault cuts in the EK wells were matched to the seismic data.

In horizons mapping and interpretation, laterally consistent seismic reflectors were also tracked. These were to detect hydrocarbon bearing structures, delineate their extent and calculate their volumes. The mapped events were identified from well correlation and tying well tops to seismic events. The fault-horizon earth model, resulting from the seismic interpretation provided the framework for the structural analysis of the fields.

\subsection{Well-to-Seismic Tie and Wavelet Analysis}

Well-to-Seismic tie compares seismic data at a well location with log data from the well (White and Hu, 1998) [33]. The aim is to match the measurements made through well logs, which are determined in depth domain, to the seismic data acquired in the time domain. This allows us to relate horizon tops identified in a well with specific reflections on the seismic section.

Synthetic seismic traces were generated in JGW projects and tied to seismic using well tops. This was done by using the sonic and density logs to generate acoustic impedance which in turn gave reflection coefficients. The reflection coefficient was then convolved with an extracted wavelet to generate the synthetic seismic trace. Where there exist no sonic (velocity) or density logs, a checkshot survey data was employed to give the impedances of the lithologies, from where the reflection coefficients can be deduced. The synthetic trace was compared to the real seismic data at the well location. Well log editing for the purpose of well to seismic correlation, was properly carried out.

The wavelet analysis involves the estimation of a filter, which best fits well log coefficients to the input seismic at well location. The wavelet extraction method applied in this work was model supported, using seismic and well information. A wavelet is completely defined by its amplitude spectrum (amplitude versus frequency plot) and its phase spectrum (phase shift versus frequency plot). The wavelet can be estimated in various ways depending on the information available. Well-to-seismic tie is a crucial step in seismic interpretation and inversion.

\subsection{Inversion}

Controlled Sparse-spike Inversions (CSSI) were done on the two vintages using the JGW software. In this stage, acoustic impedance (AI) rock properties were estimated from seismic amplitudes and comparisons made between the synthetic and the seismic trace at the well location. Some assumptions were made as below to derive the seismic signal or wavelet:

- $\quad$ Time bulk-shift of synthetic trace is correctly determined.

- $\quad$ Reflectivity series is normal Randon or Gaussian (i.e. the seismic amplitude spectrum is equal to the reflectivity series spectrum).

The sparse-spike inversion is model driven and it assumes that only the large spikes are meaningful. It finds the location of these large spikes by examining the seismic trace. In this method the seismic trace is simulated from a minimum number of AI interfaces (or reflectivity spikes) that will reproduce the real seismic response when convolved with the wavelet. Sparse-spike inversion builds up the reflectivity sequence one spike at a time. It seeks the simplest possible reflectivity model that, when convolved with the wavelet, produces a synthetic that matches the input seismic. The Sparse-spike solution does not have any low frequency components due to the band limited nature of input seismic. The constrained option uses a low frequency model as a guide. The low frequency variation was estimated from filtered well logs and this gives better results. The inverted vintages were interpreted, and the amounts of change in the reservoir were defined by the differences between the base and the monitor seismic.

\section{Results}

The results of the study were sequentially presented as maps, tables, graphs and sections.

\subsection{Structural and Seismic-to-well tie analyses}

The structural analysis showed dominance of NW-SE trending rollover collapsed-crest anticlines in EK with hydrocarbons trapped northwards. 
Excellent synthetic seismograms were generated for the tie. It is essential to note that the well logs receive editing ("QCed"), to limit the number of bad data points. The well logs were correlated to the seismic data which enabled the constraining to the zone and horizon of interest. The starting point of this geophysical interpretation is the correlation of the well logs to the seismic data using the seismic to well tie plug-in of the Shell nDi and the JGW suite. This tie analysis, enabled the identification of the reservoir loops and the correlation of the stratigraphic sequence drilled in the well to the acoustic reflections recorded in the seismic section. Hence, enabling the tying of borehole formation tops identified in the well with specific reflectors on the seismic section. Each peak from the synthetic is correlated from each peak from the real seismic trace. The results showed good ties between the well's logs and the seismic data, considering the alignment of the events on the well synthetic trace and the field acquired seismic trace as can be seen in Figures 5 to 7 . Figures 5 and 6 are the result of the tie for well EK -39 while Figures 7 (a, and b) is that for the side track of EK -39 (i.e. EK -39_ST).

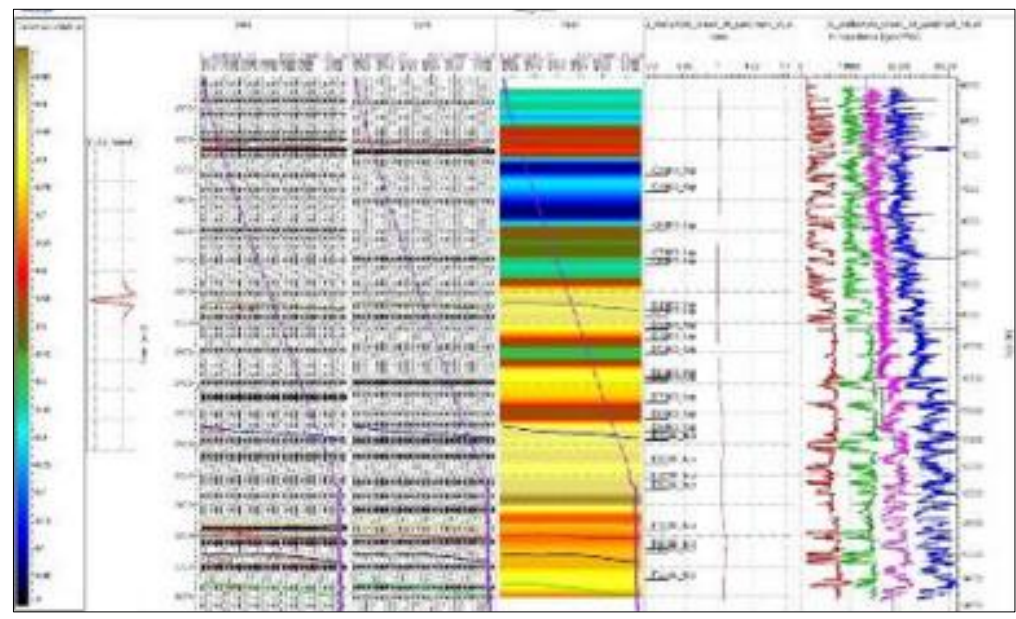

Figure 5 Well-to-seismic tie of EK - 39 using JGW software (seismic trace passing through well is repeated)

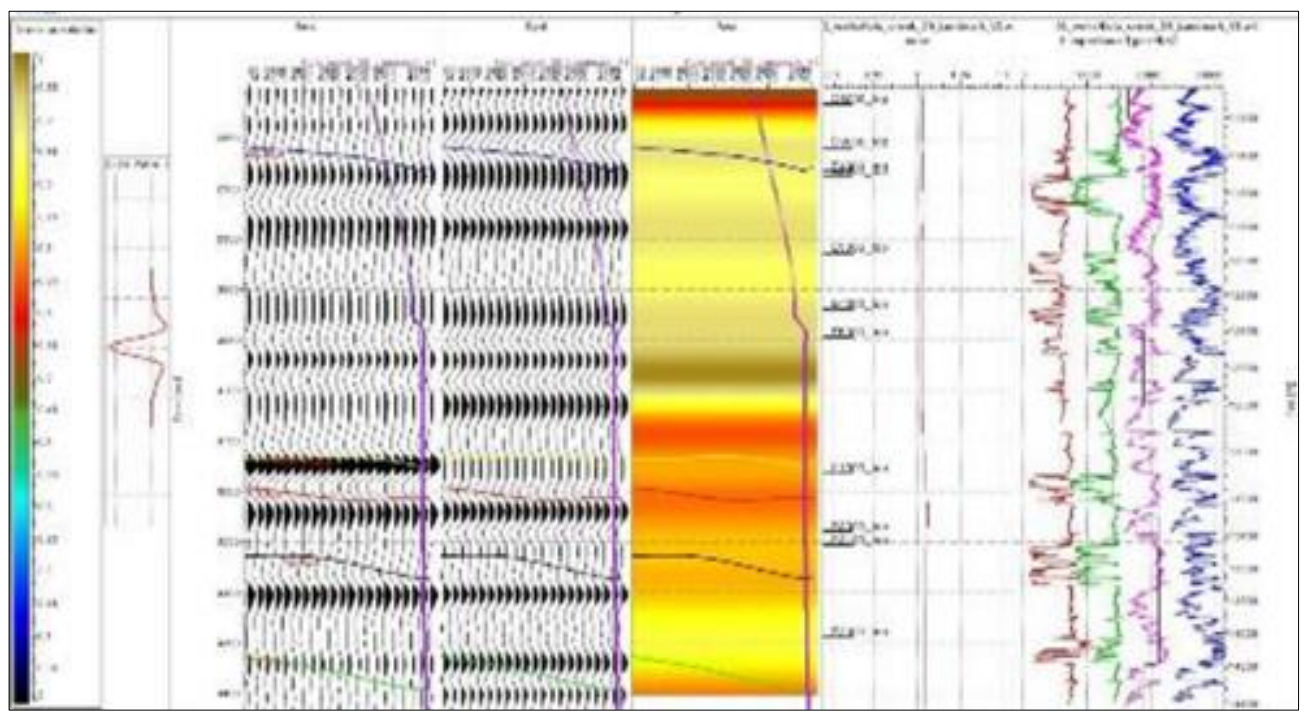

Figure 6 Well-to-seismic tie of EK - 39 (Zoomed at F Reservoirs)

Figure 8 (a, and b) show the wavelet extracted from seismic and well log data of well EK 39 and EK 39_ST respectively. Wavelet extraction was performed in order to carry out a good well-to-seismic tie. This is to ensure that a wavelet which is zero-phase and has same amplitude spectrum with that of the seismic data was used and this was achieved. Wavelet estimation was an iterative process that improved as the synthetic tie improved. The result showed the statistical and the well based wavelets. The statistical wavelet was obtained from seismic data while the well based wavelet was obtained from well log data. The wavelet extracted represents the average of the wavelets of the individual well control points. This gives approximate values of the true, the amplitude and phase spectra of the source wavelet. The wavelets 
show amplitude and phase spectra; therefore, in the case of the seismic extraction, a zero/ constant phased wavelets were assumed. In order to get the best correlation, the statistical wavelet extraction is followed by a well-based wavelet extraction.

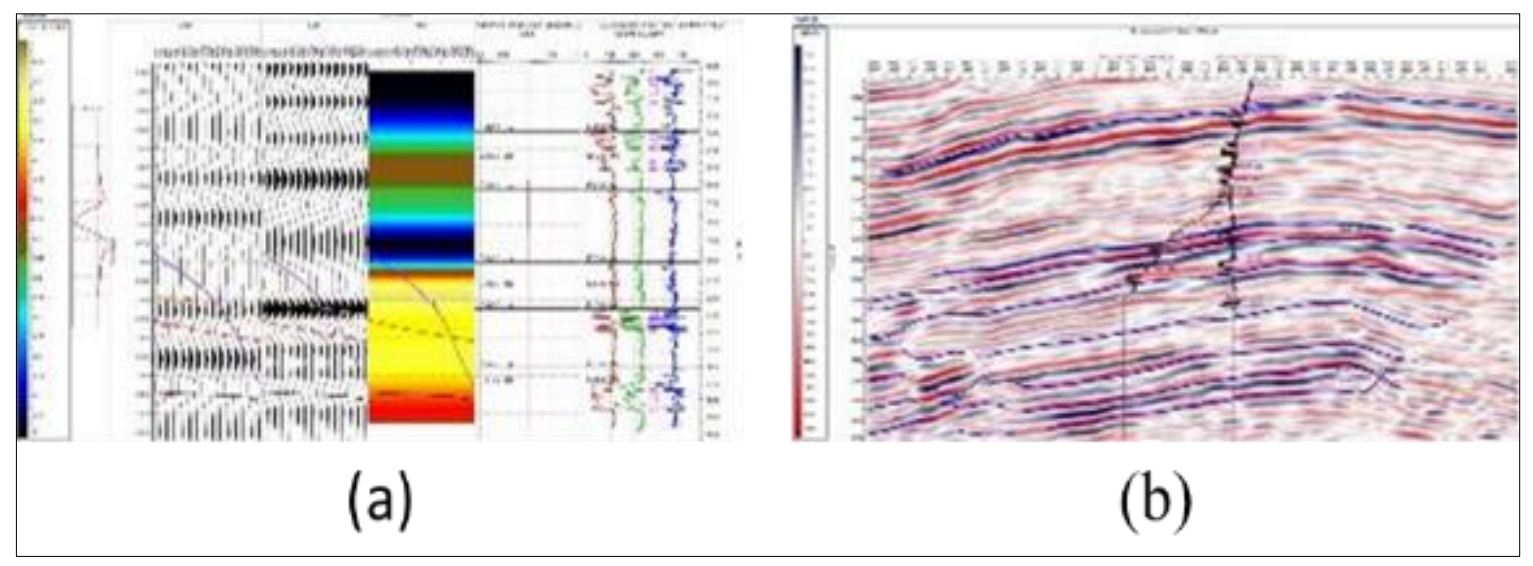

Figure 7(a, and b): Well-to-seismic tie of EK -39_ST

Generally, overall well-to-seismic tie at wells EK 39 and 39_ST were good. EK 39_ST gives moderate tie since it does not have any measured sonic log (used synthetic sonic log for tie).Wavelet extracted from EK 39 is consistent in amplitude and phase and hence was used in the inversion.

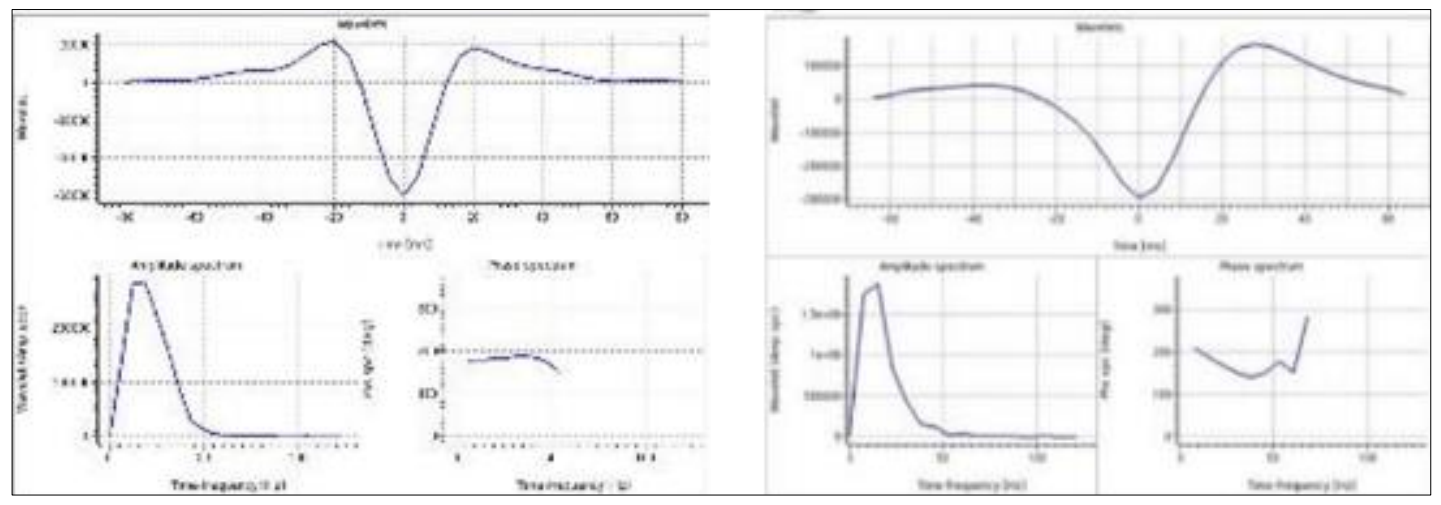

Figure 8 (a). EK -39 Wavelets (b). EK -39_ST Wavelets

\subsection{The Constrained Sparse-Spike Inversion (CSSI) Results}

The results are presented in Figures 9 where comparisons were made between the amplitude sections and the inverted section of EK Base and monitor seismic vintages. As a result of production changes (pressure and saturation decline), E2000 top have move up to a current position as seen in the monitor seismic as compared with the base. Also the band pass AI section through well EK-1 (within 2500-3000ms), have also indicated the extent of the oil-water contact (OWC) movement.

\subsection{Comparing Acoustic Impedance Volumes}

The acoustic impedance volumes shown in Figure 10 are cross sections of the Base and the Monitor seismic data from $\mathrm{X}$-line: $2875 \mathrm{~ms}$ to $2965 \mathrm{~ms}$ with inserted tops and base (horizons) of the reservoir and the legend showing colours of high and low AI. Within these horizons, a reduction in the impedance contrasts from the base, to the monitor were observed which can be interpreted as the result of production effect in the reservoir. Also high resistivity values as seen from EK 39 well log almost aligning with the low impedance section within the reservoir which indicated hydrocarbon charged zone as can also be correlated with Figures 9 and 10. 


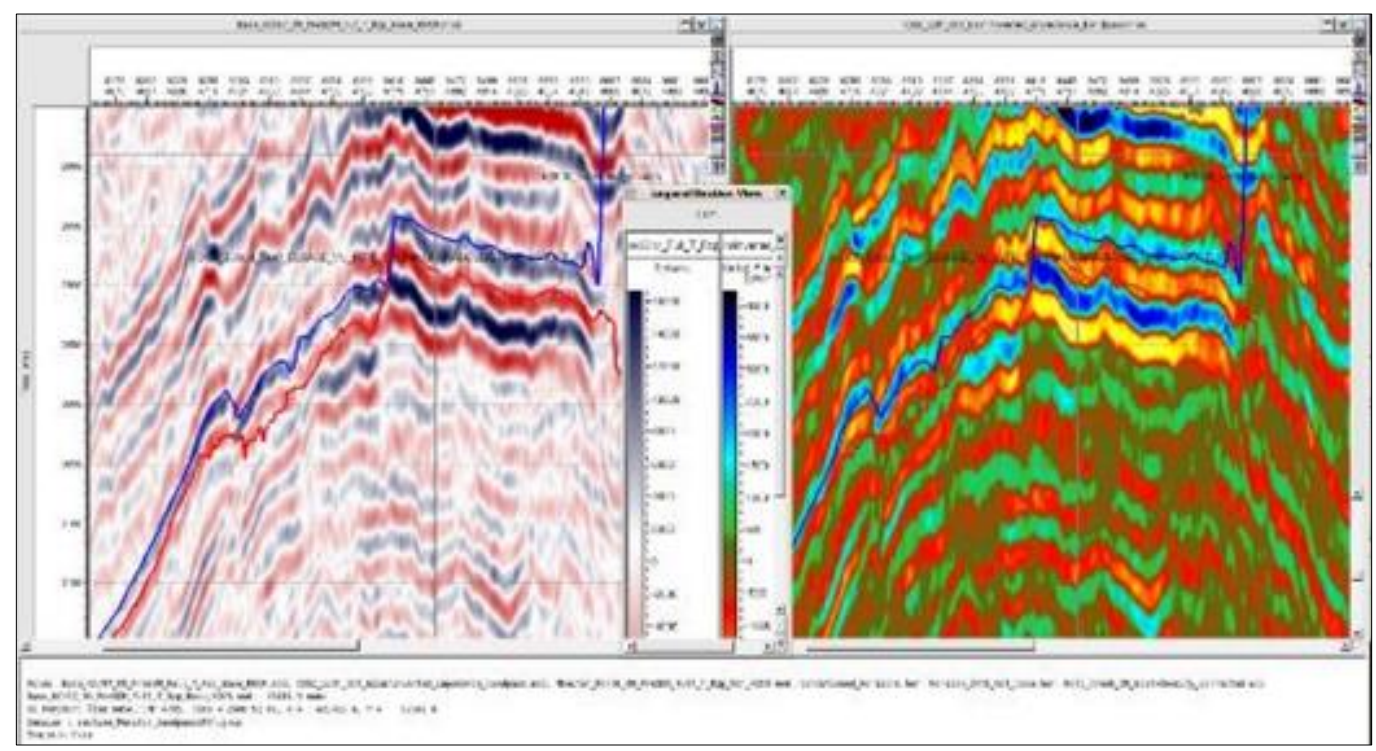

Figure 9a Juxtaposing the amplitude section with the inverted section of EK Base seismic Vintage

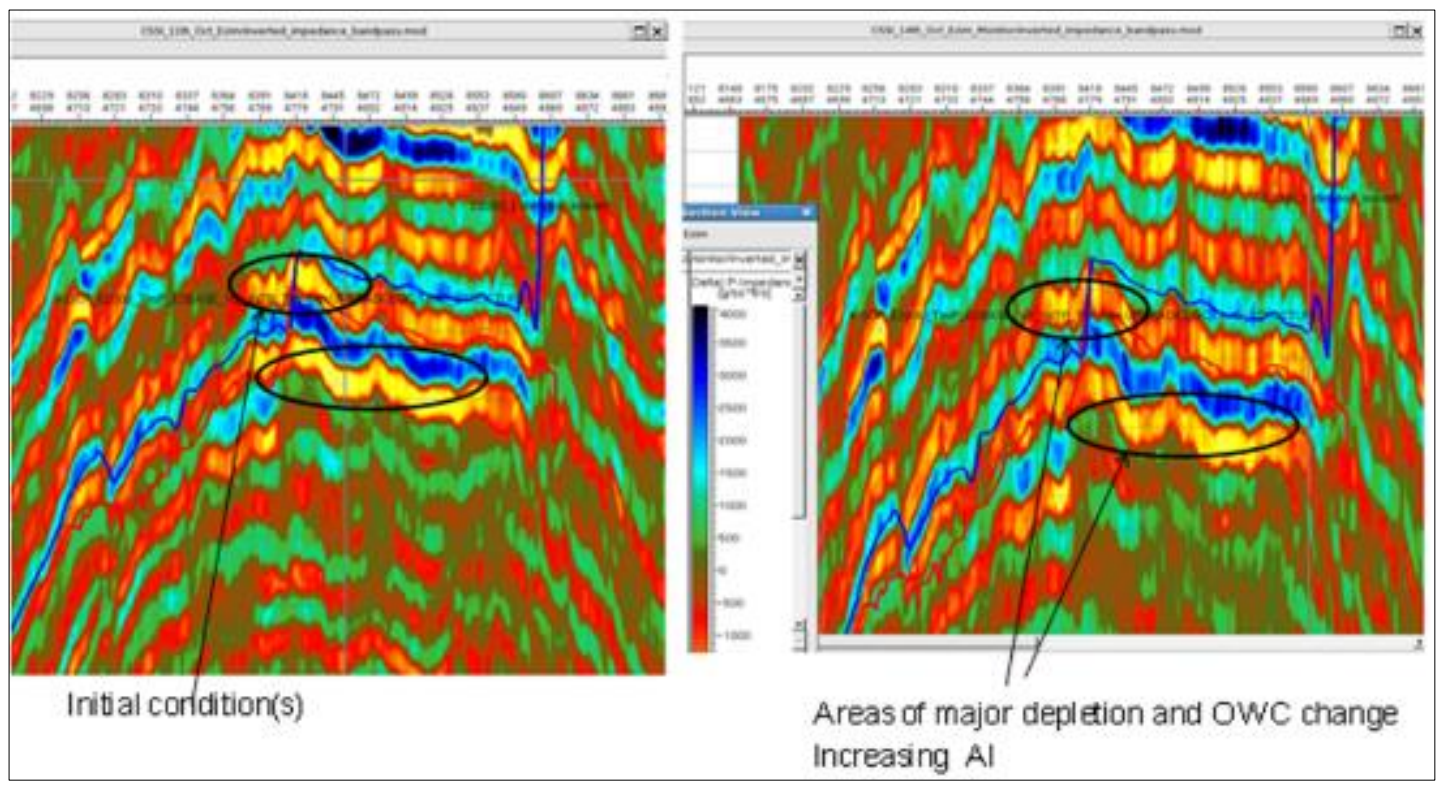

Figure 10 Section of Band pass P-impedance of the EK-Field 4-D CSSI showing the production changes over time (2875-2965ms)

Production from EK Field over the years, were seen to alter some of the petrophysical properties (example lower hydrocarbon saturation values for wells drilled later as a result of water influx). In order to minimize this impact, several measures were adopted including: using core derived saturation as against log saturation, in the volumetric calculations. The AI inversion result of the base and monitor difference (depletion in the monitor) have shown the production effects.

As a result of production changes, E2000 top have move up to a current position as seen in the monitor seismic as compared with the base. Also the band pass AI section through well EK -39 (within 2500 - 3000ms), have also indicated the extent of the oil-water contact (OWC) movement (Figure 11). The monitor seismic and the inverted (band pass AI) section through EK -27, -39 (within $2500 \mathrm{~ms}-3000 \mathrm{~ms}$ ), have also indicated E2000 depletion and the extent of the present non uniform gas oil contact (GOC) and oil water contact (OWC) movements, in EK -03 and EK -16 from 11660 $\mathrm{ft}$ to $11730 \mathrm{ft}$ and from $11918 \mathrm{ft}$ to $11852 \mathrm{ft}$ respectively (Figures 10 and 11). These results made it easier to also find more prolific prospects, propose EK - 40, - 42 wells, while accurately pick their drilling locations and screen depths. 
Figures 12 (a, b, and c) show amplitude maps (Band pass P-Impedance) results of the EK Field, 4-D CSSI and production changes over time.

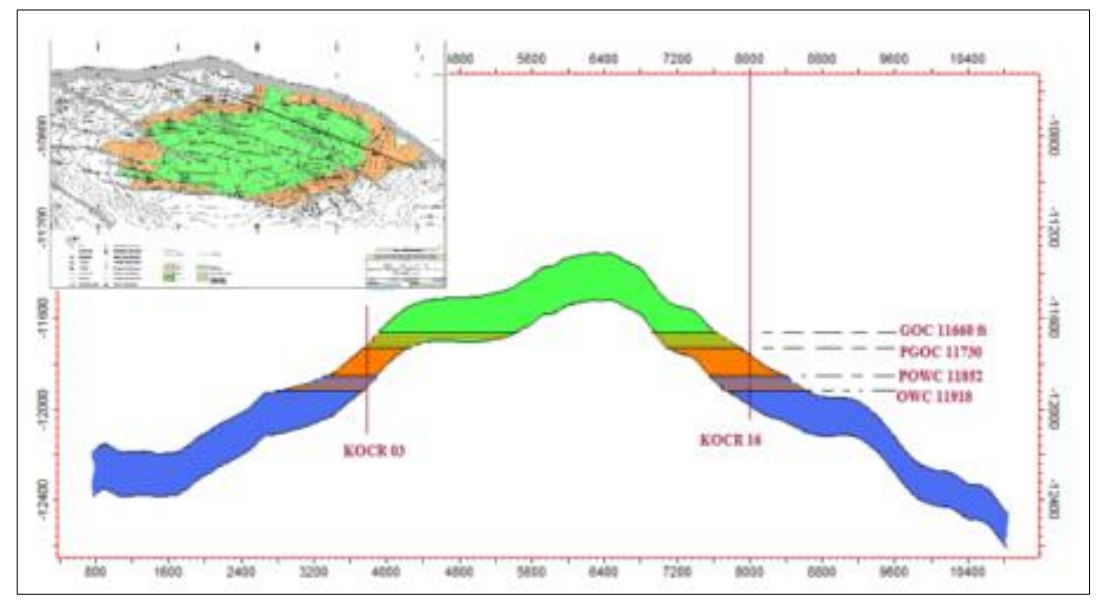

Figure 11 E2000 Cross section through EK -03 and EK -16

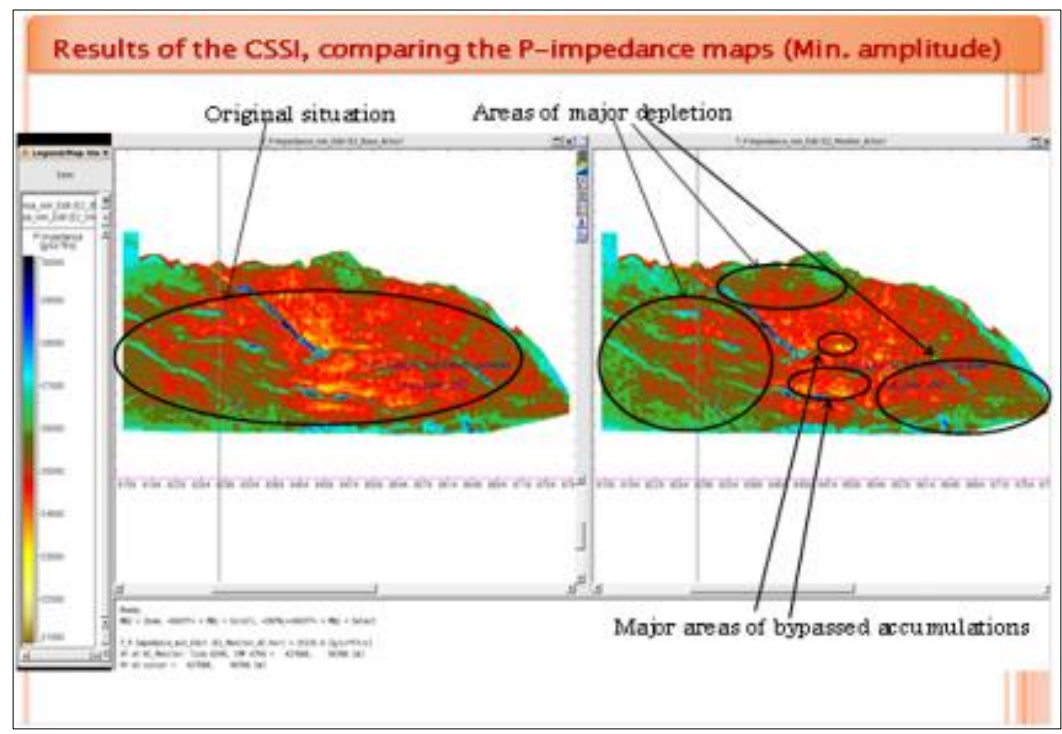

Figure 12a Map showing Band pass P-Impedance results of the EK Field 4-D CSSI and production changes over time

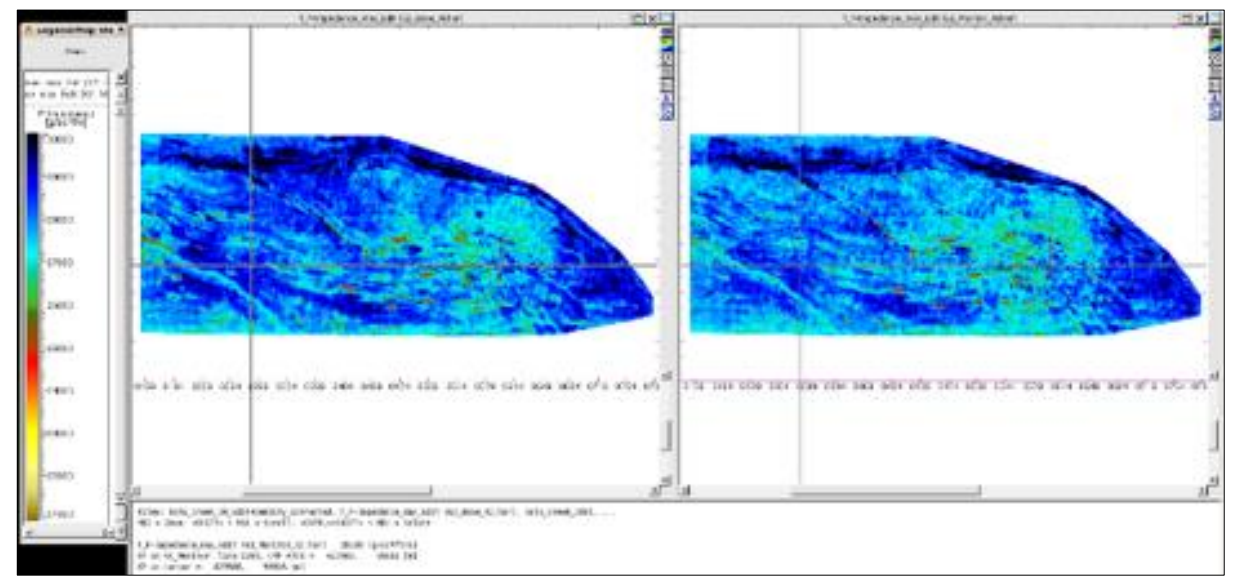

Figure 12b Map showing Band pass P-Impedance comparison Max-Amplitude of the EK Field 4-D CSSI and production changes over time 


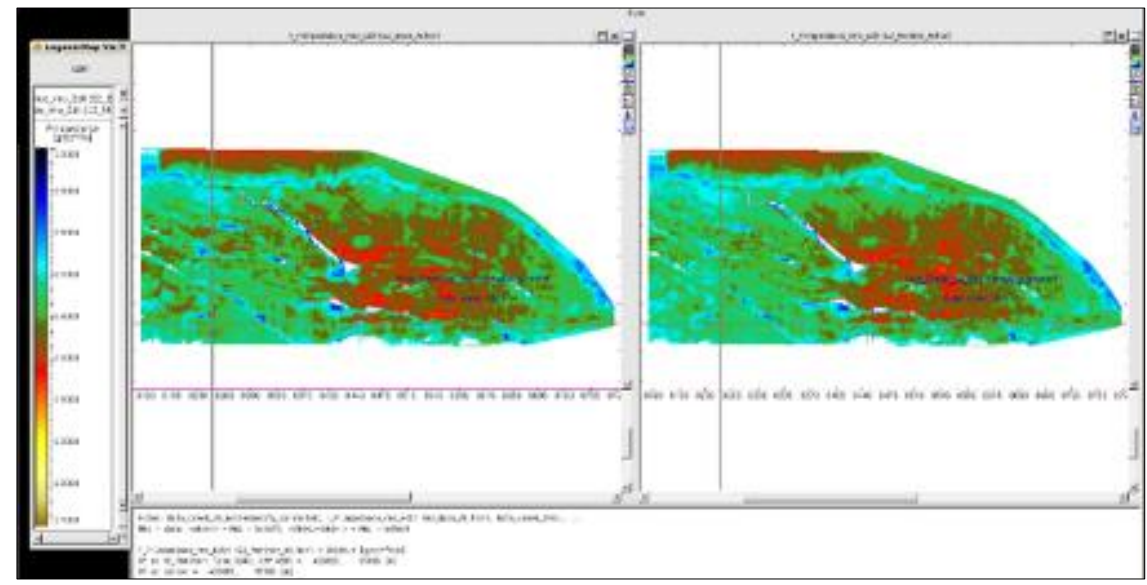

Figure 12c Map showing Band pass P- Impedance comparison RMS-Amplitude of the EK Field 4-D CSSI and production changes over time

\subsection{Acoustic Impedance Sections and Difference}

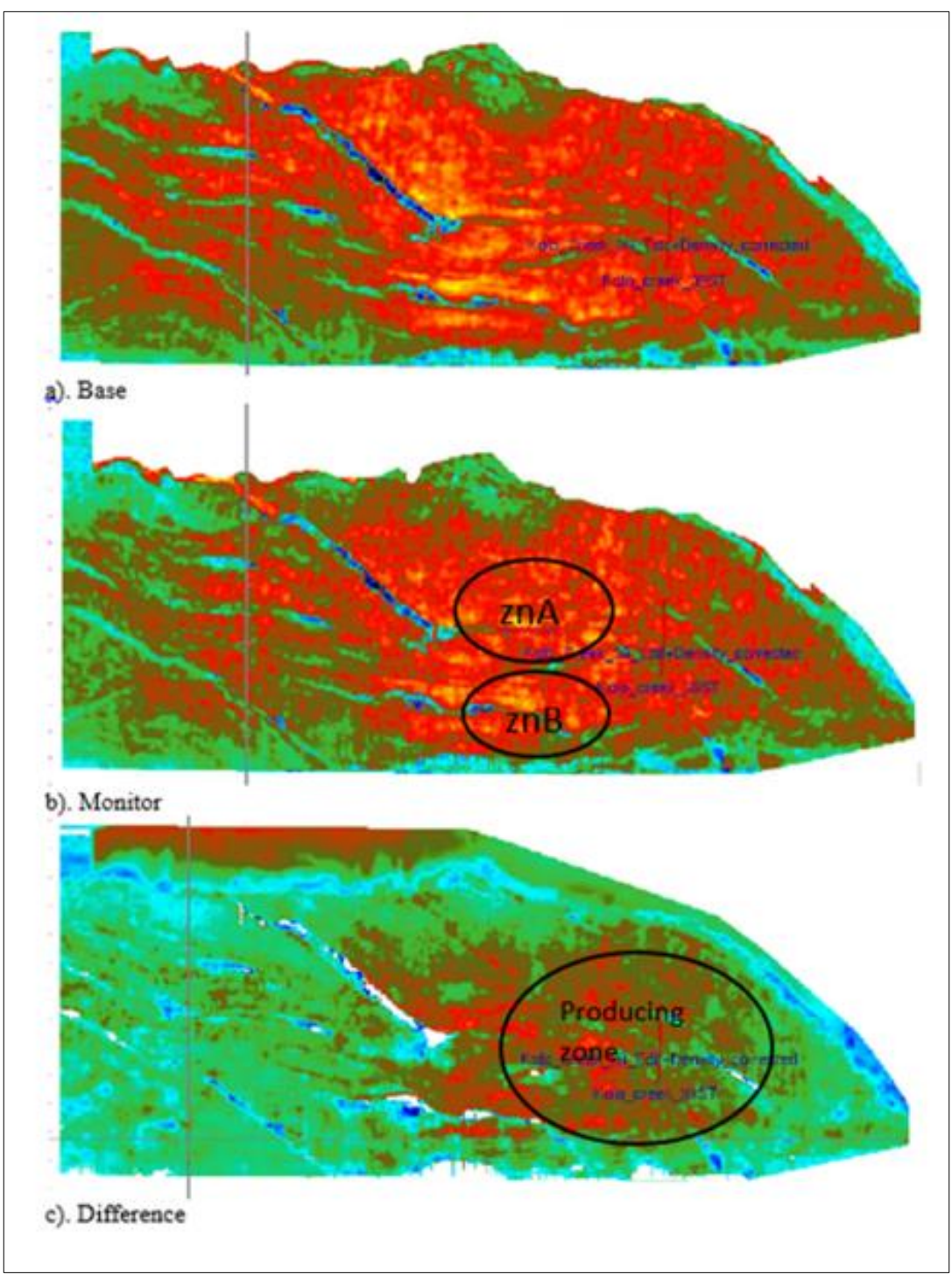

Figure 13 Acoustic Impedance Slices (RMS) taken at EK-E2000 seismic horizon from Base Monitor (b) and Difference (Monitor-Base c) 
Figures 13 and 14 shows the acoustic impedance slices taken at the E2000 top and base horizons for the base (a), monitor (b) and difference (c) volumes showed low acoustic impedance values corresponding to hydrocarbon charged sand bodies around the producing well locations.

A slight decrease is observed in the Monitor when compared to the Base which may be attributed to hydrocarbon migration effects. Probable by-passed zones with low acoustic impedance anomalies were also observed west and north-west of the producing zone. Also two zones (A and B) below, were observed, which may be hydrocarbon charged sand bodies since they exhibited consistently low acoustic impedance values in both the Base and the Monitor and is much pronounced in the Monitor than the Base which may be attributed to hydrocarbon accumulation. 4-D effect was observed on the Difference slice due to changes in acoustic impedance around the well location. Regions having large 4-D change in the difference seismic volumes are affected by production since the base and monitor seismic volume were repeatable.

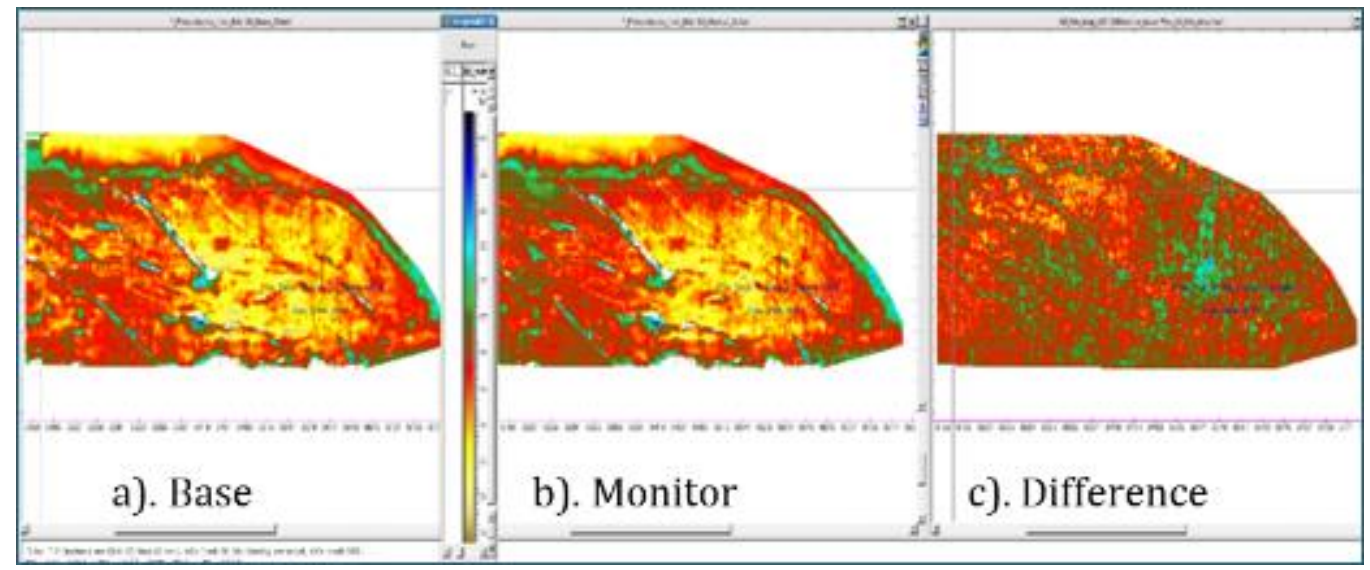

Figure 14 Result showing map of the EK Field -E2000, 4-D Seismic band pass P. Impedance CSSI; a) is an amplitude extraction from the preproduction baseline survey (1997); next is the amplitude extraction at the same level from the 2012 re-processed monitor; next is the amplitude extraction from the seismic difference cube highlighting areas where water has replaced oil

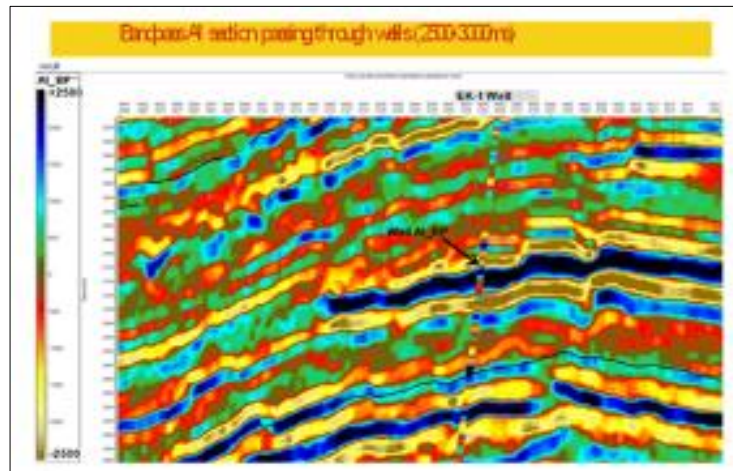

(a)

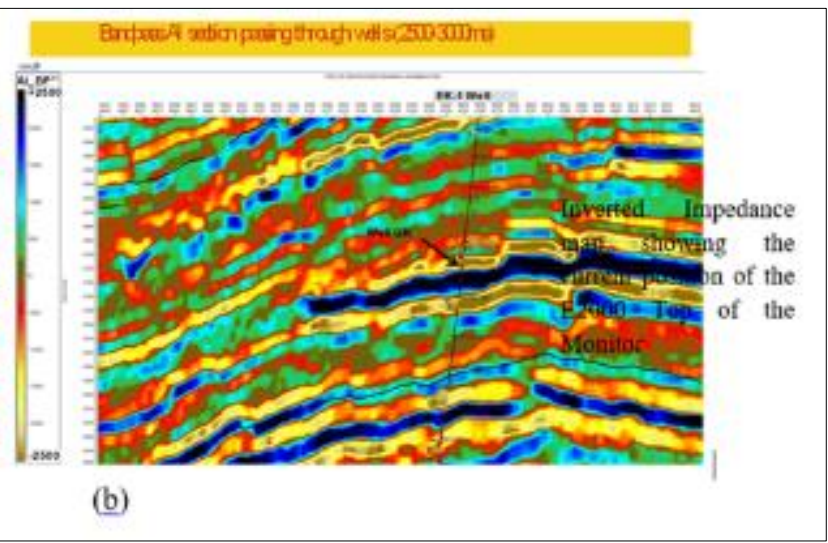

(b)

Figure 15 Band pass AI section passing through wells EK-1 (within 2500-3000ms) \{Note: Soft impedance bodies (yellow and red), indicates sands while Hard impedance bodies (blue and black) indicates shale). a) Tied with well AI-Band pass (b) tied with GR log

\subsection{Time-lapse Interpretation}

In summary, the left/ western side of the impedance map of EK Field has shown much depletion than the right side bounded by the major fault. The central of this side forms prospect areas of focus. Consequent to the Symptoms of decline, the proposed Oil Rim Development (ORD) wells on E2000 might need some better lift assistance. 
The interpretation of time-lapse seismic data requires integration of rock physics, geology, and production information. Anomalies in the time-lapse acoustic impedance difference data are most commonly caused by pressure or saturation changes or non-repeatable noise. Away from the low fold margins of the survey, there are no major difference anomalies above the reservoir interval (Figures 12 to 14). It is not possible to separate pressure and saturation time-lapse seismic effects using only the stacked P-wave derived data. However, integration with other information can help discriminate the primary cause. The absence of a time-lapse anomaly can be attributed to no reservoir changes, counter-acting pressure and saturation changes, non-repeatability, and the lack of reservoir.

It will be worthwhile to note from Figures 15 that the hydrocarbon have pushed above the initial perforation due to production and increased water influx. Hence, the use of 4-D results to optimize the positioning of development wells and to constrain and update the dynamic reservoir models. A comparison of the impedance inversion results with the interpreted base and top of the EK - Agbada Sandstone from the well ties shows generally good agreement.

\section{Discussion}

This research was carried out in order to more accurately resolve seismic monitoring of reservoir properties and their changes over time. The EK Field offer unique opportunities to develop these high resolution reservoir characterization and monitoring methodologies. Also, the work will contribute to knowledge and analyse the importance of time-lapse seismic in reservoir monitoring for identifying Oil Water Contact (OWC), Gas Oil Contact (GOC), drained and un-drained reservoir compartments (by passed hydrocarbon), and optimising well placement.

Application of 4-D seismic inversions has been well-known to be a useful tool for reservoir management and its significances has been recognized, worldwide from monitoring production to identifying producing zones and deeper bypassed hydrocarbon. The CSSI has also exhibited vital role in providing relevant information in the vast streams of data under the constraints of lower cost and less time in the interpretation of seismic data and less human-labour are required.

However, this understanding has financial significance in that the recovery factor of a reservoir can be improved by few percentages and the return on investment can be maximised and proper decisions on areas of divestment. This study is significant in the sense that:

It is aiding in the improvement of production, enhancing the well placement within the Niger Delta and optimises the design of asset recovery and divestment processes. It would help to rejuvenate oil fields and enhance the ability to predict future reservoir and also estimate hydrocarbon reserves of the Niger Delta Basin.

The results were crucial to addressing the inherent reservoir monitoring problems in those areas. Furthermore, the research have not only build a model that is consistent with current geological, geophysical and petrophysical data; but have built one that gives a good prediction of its future behaviour (history matching).

The outcome is an important contribution to the academic knowledge base and also to the oil and gas industry as modern exploration is now focused at optimizing field developments and production, minimizing costs and maximizing the economic returns of the assets.

E2000 sands have good well coverage and lower structural uncertainties. There are varying fluid contacts in the E2000 reservoir levels. The significant risks identified for the EK field is the vandalisation of the oil/gas export lines which affects the field's production.

\section{Conclusion}

The time-lapse program at EK has proved to be a cost-effective tool for reservoir surveillance. A number of factors contributed to its success: application of an efficient and robust interpretation strategy established using 4-D seismic models based on reservoir flow simulation. Time-lapse (4-D) seismic is a reservoir monitoring technology that has matured to the point where it can be considered a reliable reservoir surveillance tool. We have seen in this paper that the applications of time-lapse seismic methods have helped to determine the extent of the oil-water contact (OWC) movement during the years of production. 4-D is of benefit in identifying connectivity and fault sealing. Identify thief zones, water/gas coning and cusping. Some of the economic benefits include: increase/accelerate ultimate HC recovery, Reduce infill well costs; reduce water/gas separation requirements (delay water/gas breakthrough). 
This study has enabled the location of deeper bypassed hydrocarbons with improved recovery. It has also, helped in effective well plans with new integrated technologies. This will improve reservoir monitoring and property prediction of deeper plays in the Niger Delta.

\section{Compliance with ethical standards}

\section{Acknowledgments}

The authors acknowledge the contributions of Prof. Olugbenga Ehinola (Department of Geology, University of Ibadan); Professor Okwudiri Anyiam (Department of Geology, University of Nigeria), Dr. Yaqub Adepoju, and Otuka Umahi to this study at the initial stage. The Management of SPDC's Geosolutions Department including, Sam Ezugworie, Dr. Bertrand Ozumba, Basak Prahlad, Dr. Meshach Omudu, granted me the research internship opportunity and their facilities including work stations and research data were used. They are highly appreciated.

\section{Disclosure of conflict of interest}

No conflict of interest.

\section{References}

[1] Aikulola U, Kanu M, Quadt E, Olotu S, Osayande N. Onshore 4D processing: Niger Delta example: Kolo Creek case study, SEG San Antonio 2011 annual meeting. 2011; 4175-4179.

[2] Blonk E, Brehen R. Feasibility of 4-D seismic monitoring: The Leading Edge (TLE). 1998; 11(6): 1315-1317.

[3] Burkhart T, Hoover AR, Flemings PB. Time-lapse (4-D) seismic monitoring of primary production of turbidite reservoirs at South Timbalier Block 295, offshore Louisiana, Gulf of Mexico, Geophysics. 2001; 65: 351-367.

[4] Calvert R. Insights and methods for 4D reservoir monitoring and characterization. EAGE/ SEG Distinguish ed Instructor Short Course. 2005; 8.

[5] Chi CY, Mendel JM, Hampson D. A computationally fast approach to maximum-likelihood deconvolution: Geophysics. 1984; 49(05): 550-565.

[6] Detomo Jr Gouveia W, Hatchell PJ, Legius E, Mcclenaghan R, Weaver S. Initial interpretation results from the Bonga 4D Time-Lapse Seismic. I. Al-Mandhary, SEG 2009, Houston. 2009.

[7] Ecker C, Lumley DE, Tura A, Kempner W, Klonsky L. Estimating separate steam thickness and temperature maps from 4-D seismic data: An example from San Joaquin Valley, California. 69th Annual International Mtg., Society of Exploration Geophysicists (SEG), Expanded Abstracts. 1999; 2032-2034.

[8] Eiken 0, Haugen GU, Schonewille M, Duijndam A. A proven method for acquiring highly repeatable towed streamer seismic data; Geophysics. 2003; 68 (4): 1303-1309.

[9] Energy Information Administration. Natural Gas 1998 Issues and Trends; Office of Oil and Gas, U.S. Department of Energy, Washington, DC. 1998(a); 20585, 260P.

[10] Gan L, Yao F, Hu Y, Liu Y, Du W. Applying 4D seismic to monitoring water drive reservoir, Society of Exploration Geophysicists SEG Expanded Abstracts. 2004; 23: 2553.

[11] Haak RC, Sunderaramam P, Diedjomahor JO, Xiao H, Grant NJ, May ED, Kelsch K. Niger Delta Petroleum Systems, Nigeria: In Mello, M.R. and Kats, B.J. (Eds.), Petroleum Systems of South Atlantic Margins. American Association of Petroleum Geologist (AAPG) Memoir, No. 73: 231.

[12] Kulke H. Nigeria, in, Kulke, H., (Ed.): Regional petroleum geology of the world. Part II: Africa, America, Australia and Antarctica: Berlin, GebrüderBorntraeger. 1995; 143-172.

[13] Lorenzen. Inversion of multi-component time-lapse seismic data for reservoir characterization of Vacuum Field, New Mexico, A PhD thesis submitted to Colorado School of Mines, Golden-USA. 2000.

[14] Lumley DE, Nunns AG, Delorme G, Adeogba AA, Bee MF. Meren Field, Nigeria: 4-D Seismic case study. 69th Annual International Management, Forum of the Society of Exploration Geophysicist (SEG), Expanded Abstracts. 1999; 1628-1631.

[15] Lumley DE. Time-lapse seismic reservoir monitoring, Geophysics. 2001; 66(1): 50-53. (January - February 2001) 
[16] Lumley DE. Business and technology challenges for 4D seismic reservoir monitoring: The Leading Edge (TLE). 2004; 23(11): 1166-1168.

[17] Omudu LM, Ebeniro JO. Cross-Plot and Descriptive Statistics for Lithology and Fluid Discrimination: A Case Study from Onshore Niger Delta: Presented at the 2007 Annual Meeting of NAPE, Abuja. 2007a.

[18] Omudu ML, Ebeniro JO, Olotu S. Optimizing Quantitative Interpretation for Reservoir Characterization: Case Study Onshore Niger Delta: A paper presented at the $31^{\text {St }}$ Annual SPE International Technical Conference and Exhibition in Abuja, Nigeria. 2007b.

[19] Omudu ML, Ebeniro JO, Xynogalas MO, Adesanya, Osayande N. Beyond Acoustic Impedance: An onshore Niger Delta experience: 77th Annual International Mtg., Society Exploration Geophysicist, Expanded Abstracts. 2007c; 23-28.

[20] Qing L. LP Sparse-Spike impedance inversion. Hampson-Russell software services Ltd. 2002; 14.

[21] Reijers TJA. Stratigraphy and sedimentology of the Niger Delta; Geologos. 2011; 17(3): 133-162.

[22] Ross C, Suat-Altan M. Time-lapse seismic monitoring: measurement strategies and techniques. The Leading Edge (TLE). 1997; 1021-1027.

[23] Russell BH. Introduction to seismic inversion methods: Society of Exploration Geophysicist (SEG) Course Notes Series. 1988; 2.

[24] Sarkar S, Wences P, David H. On the inversion of time-lapse seismic data - The Leading Edge (TLE), Society for Exploration Geophysics (SEG). 2003; 788-790.

[25] Shell Petroleum Development Company (SPDC), Geomatics Department. Map of Niger Delta Showing the Depobelts, Relief and Sea floor topography, Geomatics ArcGIS ver. 2008; 8.0.

[26] Shell Petroleum Development Company (SPDC), Nigeria. Resource Change Control Note (RCCN), Kolo Creek Field Development Plan. 2013.

[27] Short KC, Stauble AJ. Outline of geology of the Niger Delta: American Association of Petroleum Geologists (AAPG) Bulletin. 1967; 51: 761-779.

[28] Staples R, Stammeijer J, Jones S, Brain J, Smit F, Hatchell P. Time-Lapse (4D) Seismic Monitoring - Expanding Applications, 2006 CSEG/CSPG/CWLS, Calgary; Expanded abstracts. 2006.

[29] Tian S, MacBeth C, Shams A. An Engineering-consistent Inversion of Time-lapse Seismic Data: $74^{\text {th }}$ Annual Conference and Exhibition, EAGE, Expanded Abstracts, Copenhagen, Denmark June 2012.

[30] Treitel S, Lines LR. Geophysical inversion and application: Memorial University of Newfoundland. 1994.

[31] Tura A, LumleyDE. Estimating pressure and saturation changes from time-lapse 'AVO' data; 69th Annual International Meeting: Society for Exploration. Geophysicists (SEG) Expanded Abstracts. 1999; 1655-1658.

[32] Waal HW, Calvert R. Overview of global 4D seismic implementation strategy, Petroleum Geoscience. 2003; 9(01): 1.

[33] White RE, Hu T. How accurate can a well tie be? The Leading Edge (TLE). 1998; 18(8): 1065-1071.

[34] Widmaier M, Hegna S, Smit F, Tijdens E. A strategy for optimal marine 4D acquisition: 73rd Annual Meeting, Society for Exploration Geophysics SEG. 2003; 1533-1536.

[35] Zou Y, Bentley LR, Lines LR. Time-lapse seismic modelling of the Pikes Peak Field: CREWES Research Report. 2002; 14. 